\title{
A ESTIGMATIZAÇÃO DO SUJEITO INFRATOR SOB A ÓTICA DOS ANTECEDENTES CRIMINAIS NAS DECISÕES JUDICIAIS QUE DECRETAM A PRISÃO PREVENTIVA
}

\section{VICTIMISATION INFRINGING THE SUBJECT UNDER THE PERSPECTIVE OF BACKGROUND CRIMINAL JUDGMENTS IN DECREE THAT A PROBATION}

\section{Resumo}

O presente trabalho científico, por meio da pesquisa bibliográfica, tem como objetivo discorrer sobre o instituto dos antecedentes criminais e sua influência nos decretos de prisão preventiva, à luz do princípio constitucional da presunção de inocência. Procura-se delinear, também, acerca da estigmatização do sujeito infrator, isto é, os maus antecedentes carregam uma roupagem subjetiva e ampla aos olhos do julgador. Utilizou-se o método de abordagem hipotético-dedutivo.

Palavras-chave: Antecedentes Criminais. Prisão Preventiva. Presunção de Inocência.

\begin{abstract}
This scientific work aims to discuss the institute of criminal record and his influence in the decrees of probation, in the light of the constitutional principle of presumption of innocence, and the criterion of reasoning used by the majority of the judges when deciding Probation. Tries to outline also about the stigmatization of the offender subject, ie, the poor record became a requisite subjective and broad.
\end{abstract}

Keywords: Criminal history. Detention. Presumption Innocence.

\section{INTRODUÇÃO}

Primeiramente, faz-se necessário conceituar antecedentes criminais no ordenamento jurídico brasileiro, bem como delinear, brevemente, acerca do seu histórico e 
quais influências geram na legislação processual penal. Após, diante de um decreto preventivo, proceder-se-á a análise da medida cautelar no Estatuto Processual Penal, seus fundamentos legais e cabimento.

Nessa esteira, haja vista a necessidade das motivações nas decisões judiciais, será percorrido o dispositivo constitucional referente ao tema, qual seja, o artigo 93, IX, da Constituição da República Federativa do Brasil de 1988, CRFB/1988, dispositivo que vincula os decretos judicias as suas respectivas motivações.

A preocupação se desenvolve ao redor da restrição da liberdade individual do agente face ao caráter negativo trazido com a certidão de antecedentes criminais. Os maus antecedentes, quando da decisão da prisão preventiva, muitas vezes, são utilizados como único fundamento para o decreto cautelar, o que, diante dos princípios da presunção de inocência e da motivação das decisões, não pode acontecer.

Desse raciocínio, surge a ideia de que as prisões automáticas, analisadas apenas com base nos maus antecedentes, não devem ser toleradas no ordenamento jurídico brasileiro, sob pena de se estar diante de decisões infundadas, abstratas e arbitrárias. Além do mais, a jurisprudência é ampla e firme ao estabelecer que o julgador deva fundamentar a prisão preventiva nas circunstâncias in concreto.

Buscou-se, ainda, pelo direito comparado, discorrer sobre a tendência de se esquecer o passado daquele que já cumpriu pena ou que já fora absolvido, como forma de se exercer o direito ao esquecimento e, em consequência, garantir o direito constitucional da presunção de inocência.

Diante da essência jurídica atinente ao tema, é fundamental que se exponha pensamentos jurisprudenciais, pois a relevância dos antecedentes criminais nas decisões que decretam a prisão preventiva é gerada pelas reiteradas decisões dos órgãos judiciais.

\section{ASPECTOS GERAIS DOS ANTECEDENTES CRIMINAIS}

Ao conceituar antecedentes criminais, Alberto Zacharias Toron traduz a ideia que se alguém não possuir registros criminais, ou seja, detentor de uma certidão vazia, considerarse-á uma pessoa sem antecedentes, tendo, portanto, bons antecedentes. Por outro lado, possuindo registros criminais, tem-se um agente de maus ou péssimos antecedentes. Nesse 
sentido, o fato de haver registro criminal é pressuposto para existência ou não de antecedentes criminais, (TORON, 1993, p. 73).

Esse mesmo autor, imerso nas ideias de Weber Martins Batista afirma que "A simples notícia, não apoiada em qualquer outra prova idônea contra o réu, de inquéritos ou processos em andamento, bem como a de arquivamentos ou absolvições por falta de provas não induzem maus antecedentes”. (TORON, 1993, p. 73-74).

O autor Hélio A. Nogues Moyano descreve sobre o agente e os antecedentes criminais no seguinte aspecto:

[...] existem apenas quatro tipos de acusados (réus ou indiciados), todos perfeitamente identificáveis. São eles: O primário sem (maus) antecedentes contra o qual não existe sentença condenatória transitada em julgado, nem antes nem depois da ocorrência do(s) novo(s) ilícito(s); o primário com (maus) antecedentes - contra o qual existe uma ou mais sentenças condenatórias (todas) transitadas em julgado após a prática de novo(s) crime(s), ou, ainda, aquele que, apesar de ter contra si sentença(s) definitiva(s), atende ao disposto no artigo 64 do $\mathrm{CP}$; o reincidente sem (maus) antecedentes - contra quem existe apenas uma sentença condenatória transitada em julgado antes da prática do ou dos novos delitos, e; o reincidente com (maus antecedentes) - quem tem contra si duas ou ais sentenças condenatórias irrecorríveis, sendo que, pelo menos uma delas, transitou em julgado antes da prática da ou das infrações e não se adapta ao dispositivo no referido artigo 64 do CP. (MOYANO, Boletim IBCCrim, São Paulo, n. 8, p. 3, set. 1993).

Para Francisco Bissoli Filho, antecedentes ou precedentes, também assim chamados, consistem em todos os atos, condutas e episódios, próximos ou remotos, positivos ou negativos, da vida individual, familiar, profissional, intelectual e social do agente, que possam interessar, de qualquer modo, à aferição subjetiva do delito e da personalidade do agente. (BISSOLI, 1998, p. 59)

Historicamente, frisa-se que, entre a Idade Média e o Iluminismo, o instituto dos antecedentes criminais não restou evidenciado ou delimitado, já que, naquela época, o ordenamento penal se voltava para a punição. É dizer que o juiz, detentor de poder, aliado à publicidade dada aos casos ilícitos, aplicava a sanção, cruelmente, de forma que informava toda a sociedade. (COSTA, 1985, p. 34-35).

Naquela época medieval, destacava-se a intensidade da sanção e da publicidade nos casos em que se tinha notícia da prática de algum crime, razão pela qual o Estado exercia um controle social por meio do estigma e da infâmia.

Tanto o estigma, quanto à infâmia, caracterizavam-se ao se dar publicidade à sanção imposta ao acusado e pelo caráter cruel da aplicação da pena. Tal crueldade poderia ser evidenciada pelos registros das mutilações, as quais, nesta época medieval, aconteciam pela retirada dos dedos, das mãos ou dos pés, de olhos, entre outros meios cruéis de sanção. 
Nesse raciocínio, observa-se o caráter "estigmatizante" daquele que praticava crime, já que, pela mutilação, era possível identificar que determinada pessoa havia sido autor de um delito. (COSTA, 1985, p. 51-56).

Com as revoluções históricas e com as conquistas de direitos individuais, alguns países da Europa passaram a adotar mecanismos facilitadores na identificação de pessoas com antecedentes criminais e começaram a desenvolver cadastros referentes aos dados e anotações criminais. (COSTA, 1985, p. 99-100).

Passando para uma análise mais próxima, o Código Filipino, quando das Ordenações do Reino de Portugal, evidenciava uma preocupação com a personalidade daquele que houvesse praticado algum delito, razão pela qual surgiram, naquela época, as chamadas folhas ou folhas corridas. (PIERANGELLI, 2001, p.198).

Essas anotações também advertiam os corretores de folhas, bem como os juízes, quando da soltura do réu. Nessa oportunidade, criou-se o rol de culpados, instrumento no qual ficavam registrados os nomes dos autores condenados criminalmente. (PIERANGELLI, 2001, p. 198-199).

Segundo Francisco Bissoli Filho, o Código Penal Brasileiro - CP, Decreto-lei $\mathrm{n}^{\circ} 2.848$ de 1940 restou influenciado pelo positivismo que fez com que os antecedentes passassem a ser um fator relevante na aplicação da pena, isto porque, segundo esta escola, o 'homem criminoso' é o objeto da investigação (BISSOLI, 1998, p.61).

Na visão conceitual de Salo de Carvalho (2001, p. 111-112), bem como de Francisco Bissoli Filho (1998, p. 64), o que caracteriza os antecedentes criminais são a amplitude, a negatividade, a subjetividade, a relatividade e a perpetuidade.

Desse campo de características, a amplitude está ligada ao fato de o agente estar envolvido a quaisquer casos passados, bons ou ruins, que podem ser levados em conta como antecedentes (BISSOLI, 1998, p. 64).

Embora se diga que os antecedentes possuem uma roupagem ampla, não se deve, porém, caracterizar esta amplitude como absoluta, tendo em vista as relações privadas que não geram consequências no campo criminal. (TORON, 1993, p. 74).

No que tange à negatividade, destaca-se que, dentro do conceito de antecedentes criminais, fatos anteriores à conduta do agente, tem-se somente a busca dos fatos negativos do indivíduo, descartando as condutas boas ou ótimas e baseando-se apenas nos registros policiais e judiciais.

Consoante Bissoli, liga-se a subjetividade à interpretação dada aos antecedentes, seja esta análise feita por critérios individuais ou sociais. (BISSOLI, 1998, p. 64). 
Tendo em vista que os antecedentes criminais são, na sua maioria, aferidos pelos registros policias e judiciais do agente, não se pode afirmar com exatidão que o indivíduo possui bons ou maus antecedentes, vez que esta análise somente se restringe a uma avaliação específica e não total da vida do sujeito (BISSOLI, 1998, p.65).

Diz-se que os antecedentes são perpétuos, em virtude deles não possuírem delimitação temporal, ao contrário do que ocorre com a reincidência, isto é, não se aplica aos antecedentes o constante do artigo 64, I, do CP.

No aspecto prático, entende-se por antecedentes os fatos anteriores, não sendo permitido contabilizar os registros policiais, judiciais, ações em trâmite, bem como quaisquer outros fatos posteriores ao delito analisado (TORON, 1993, p. 73).

Nesse sentido, tem-se o aspecto objetivo do instituto, ou seja, as decisões com trânsito em julgado, aplicação fiel do princípio constitucional da presunção de inocência constante do artigo $5^{\circ}$, LVII, da CRFB/1988.

Nessa linha de pensamento, é a posição assumida pelo Superior Tribunal de Justiça - STJ:

[...]AGRAVO REGIMENTAL. HABEAS CORPUS. CRIMES AMBIENTAIS.
DOSIMETRIA.EXASPERAÇÃO DA PENA-BASE. UTILIZAÇÃO DE
INQUERITOS E PROCESSOS EM ANDAMENTO PARA CONSIDERAR
NEGATIVA A CONDUTA SOCIAL. IMPOSSIBILIDADE. SÚMULA 444/STJ.
SANÇÃO REDIMENSIONADA. DECISÃO AGRAVADA EM
CONFORMIDADE COM A JURISPRUDÊNCIA DESTE SODALÍCIO.
RECURSO IMPROVIDO. 1. Consoante orientação já sedimentada nesta Corte
Superior, inquéritos policiais ou ações penais em andamento e condenações sem
certificação do trânsito em julgado não podem ser levados à consideração de
maus antecedentes, má conduta social ou má personalidade para a elevação da
pena-base, em obediência ao princípio da presunção de não-culpabilidade.
Exegese da Súmula 444 deste STJ. 2. Evidenciando-se que a decisão agravada
espelha o entendimento firmado por este Sodalício sobre a matéria impugnada, deve
a mesma ser mantida, pelos seus próprios fundamentos. 3. Agravo regimental
improvido. (AgRg no HC 218037 / SC. 2011/0214809-7, DJe 02/04/2014, grifo não
original).

O STJ ainda editou a súmula 444, consagrando o entendimento de se vedar a utilização de inquéritos policiais e ações penais em curso para agravar a pena-base. Assim, como consectário lógico, pode-se aplicar o raciocínio quando do decreto da prisão preventiva.

Tendo em vista o princípio constitucional da presunção de inocência, não devem ser levados em conta os registros policiais e judicias em nome do réu para efeitos de restrição da liberdade individual.

Os antecedentes criminais e a reincidência são institutos que se encontram ligados, apesar de distintos. Ambos os institutos tratam do passado do indivíduo, sendo, 
porém, a reincidência espécie dos antecedentes criminais, segundo a doutrina. (BISSOLI, 1998, p.65).

$\mathrm{O}$ instituto da reincidência é contemplado no artigo 63 do $\mathrm{CP}$, caracterizando a reincidência "quando o agente comete novo crime, depois de transitar em julgado a sentença que, no país ou no estrangeiro, o tenha condenado por crime anterior". Nisso, consoante o ordenamento jurídico brasileiro, deve-se haver condenação anterior transitada em julgado.

Veja-se:

[...] O Código Penal não define a primariedade. Seu conceito, portanto, há de ser obtido negativamente: primário é toda pessoa que não é reincidente, ou seja, que não praticou novo crime depois de ter sido definitivamente condenado, no Brasil ou no exterior, por crime anterior (CP, art. 63). Lembre-se, ainda, que a condenação anterior só funciona como pressuposto da reincidência desde que não tenha decorrido o prazo de 5 (cinco) anos entre a data de cumprimento ou extinção da pena e a prática do novo crime (período depurador). (MASSON, 2014, p.293).

Após a Lei $\mathrm{n}^{\circ}$ 6.416/1977, o CP adotou o sistema da temporariedade, o qual considera as condenações anteriores a 05 (cinco) anos para caracterizar a reincidência, in verbis:

Art. 64. Para efeito de reincidência: I - não prevalece a condenação anterior, se entre a data do cumprimento ou extinção da pena e a infração posterior tiver decorrido período de tempo superior a cinco anos, computado o período de prova da suspensão ou do livramento condicional, se não ocorrer revogação; [...].

Nessa linha de pensamento, quanto a este caráter temporal, destaca-se uma das diferenças que o instituto da reincidência criminal possui com os antecedentes, já que estes não se encontram limitados pelo tempo.

É o raciocínio de Francisco Bissoli Filho, que critica esta diferença entre os institutos. Para o autor, não faltam razões para que o ordenamento jurídico deixe de conceder aos antecedentes criminais o mesmo princípio da transitoriedade aplicado à reincidência. Segundo o autor, isso faz com que os antecedentes possuam influência de caráter perpétuo "na vida do indivíduo, mormente quando a sociedade, patrocinada por organismos estatais, procura organizar bancos de dados de infrações criminais, inclusive através de redes informatizadas, com possibilidade de acesso a inúmeros cidadãos” (BISSOLI, 1998, p.24).

\section{A PRISÃO PREVENTIVA EMBASADA NOS ANTECEDENTES CRIMINAIS E O PRINCÍPIO DA PRESUNÇÃO DE INOCÊNCIA}


Consoante Guilherme de Souza Nucci, a preventiva é a prisão cautelar por excelência, cujos requisitos encontram-se enumerados no artigo 312 do Código de Processo Penal - CPP, (NUCCI, 2011, p. 61).

Fernando Capez desenvolve o seguinte conceito de prisão preventiva:

[...] prisão processual de natureza cautelar decretada pelo juiz em qualquer fase da investigação policial ou do processo criminal, antes do trânsito em julgado da sentença, sempre que estiverem preenchidos os requisitos legais e ocorrerem os motivos autorizadores (CAPEZ, 2012, p. 328).

Segundo Fernando da Costa Tourinho Filho, no Manual de Processo Penal, a prisão preventiva é:

[...] medida precautória de índole pessoal, criando par ao indivíduo sobre o qual recai um estado mais ou menos permanente de privação de liberdade, suportada em estabelecimento adequado e é decretada pelo Juiz competente no curso de uma causa, contra imputado, com o único objetivo de assegurar sua presença em juízo e garantir eventual execução da pena. Podemos acrescentar outros objetivos: a garantia da orem pública e a preservação da instrução criminal. (TOURINHO, 1998, p. 463).

A natureza jurídica da prisão preventiva, conforme classificação doutrinária, é que esta se enquadra como modalidade de prisão provisória, ao lado da prisão em flagrante e da temporária. Segundo Fernando Capez, ela possui natureza cautelar com a finalidade de que se garanta o provimento jurisdicional superveniente. (CAPEZ, 2012, p. 328).

No que toca à legitimidade e oportunidade da sua decretação, têm-se as alterações trazidas pela lei, permitindo-se a decretação cautelar pelo juiz, de ofício, somente durante o processo, não sendo mais permitido fazê-lo, como antes, durante a investigação; e permitindo ao assistente de acusação requerê-la, não havendo essa disposição na legislação anterior, (NUCCI, 2011, p. 61).

Destaca-se que, com o advento da Lei 12.403/2011, permite-se a decretação da prisão preventiva para a garantia da ordem pública, da ordem econômica, por conveniência da instrução criminal, ou para assegurar a aplicação da lei penal, acrescentando o decreto da cautelar nos casos de descumprimento de qualquer das obrigações impostas por força de outras medidas cautelares, nos termos do artigo $282, \S 4^{\circ}$, do CPP.

A ordem pública é entendida como "estado de legalidade normal em que as autoridades exercem suas precípuas atribuições e os cidadãos as respeitam e acatam sem constrangimento ou protesto", (TOURINHO, 1998, p.475). 
Para alguns doutrinadores, afere-se esse requisito por intermédio do trinômio "gravidade da infração + repercussão social + periculosidade do agente", isto é, a gravidade de um delito autoriza a segregação cautelar na medida em que a população se revolta contra aquele crime, bem como a periculosidade do infrator, daquele que por si só é um risco, o que se afere pela ficha de antecedentes criminais. (NUCCI, 2007, p. 574).

Quanto à proteção da conveniência da instrução criminal, esta inibe que o acusado venha a prejudicar a colheita de provas, como por exemplo, a ameaça às testemunhas, a investida contra provas buscando desaparecer com evidências, ameaças ao órgão acusatório, à vítima ou ao juiz do feito, a fuga deliberada do local do crime, mudando de residência ou de cidade, para não ser reconhecido nem fornecer sua qualificação, (NUCCI, 2009, p.631).

Para assegurar a aplicação da lei penal, tem-se como costumeiro exemplo na doutrina a fuga da cidade ou do país com o objetivo de não se ver constrangido por eventual sentença condenatória, assim como a não localização do acusado no distrito de culpa (NUCCI, 2009, p. 632-633).

No tocante à garantia da ordem econômica, afirmou-se que "não se deve perder de vista os pontos já abordados, no tocante à garantia da ordem pública.” Assim, tendo a garantia da ordem econômica sofrido abalo, acarretará gravame à ordem pública (NUCCI, 2011, p.65).

Nestor Távora destaca o artigo 282, $\S 4^{\circ}$, do CPP, ou seja, o descumprimento de qualquer das obrigações impostas por força de outras medidas cautelares, tratando-se do caráter subsidiário da prisão preventiva (TÁVORA; ALENCAR, 2014, p. 735).

Dessa forma, somando-se aos requisitos supracitados, fundamentos previstos no artigo 312 do CPP, a decretação da prisão preventiva, segundo a doutrina, necessita que sejam observados os pressupostos constantes do artigo 282, I, e II, do CPP, as condições de admissibilidade previstas no artigo 313 , I, II e/ou III, parágrafo único ou art. 282 , § $4^{\circ}$, parte final, bem como o fumus comissi delicti (materialidade e indício suficiente de autoria) também previsto no artigo 312 do CPP.

Nesse prisma, deve-se destacar a presença do fumus comissi delicti e o periculum libertatis, fundamentos da prisão preventiva. Veja-se decisão do Egrégio Tribunal de Justiça de Minas Gerais:

EMENTA: HABEAS CORPUS - TRÁFICO DE DROGAS - PRISÃO PREVENTIVA - DECISÃO GENÉRICA E ABSTRATA - GARANTIA DA ORDEM PÚBLICA - AUSÊNCIA DE DEMONSTRAÇÃO REAL CONSTRANGIMENTO ILEGAL CONFIGURADO - ORDEM CONCEDIDA. - A prisão preventiva, cautelar extrema que é, exige fundamento concreto sobre o fumus comissi delicti e o periculum libertatis. Se ausentes esses pressupostos, não há 
supedâneo para a manutenção da segregação do paciente. - A motivação genérica da gravidade do delito, sem se respaldar em elementos concretos dos autos, não sustenta o decreto da prisão preventiva porque se transmuda em abstrato o "periculum libertatis" do agente. (Des. Cássio Salomé, Habeas Corpus 1.0000.13.051780-8/000).

Como exposto, para decretação da prisão preventiva, exige-se a presença dos fundamentos previstos no artigo 312, do CPP (periculum libertatis), isto é, a garantia da ordem pública, da ordem econômica, por conveniência da instrução criminal, ou para assegurar a aplicação da lei penal; bem como exige-se, também, o requisito do fumus comissi delicti (prova da existência do crime e indício suficiente de autoria), somando-se as condições de admissibilidade previstas no art. 313 do Estatuto Processual Penal.

No mesmo raciocínio de Guilherme Souza Nucci, o professor Luiz Flávio Gomes divide os requisitos da prisão preventiva no fumus boni iuris (referido fumus delicti comissi) que se caracteriza em ser a prova do crime e os indícios suficientes de autoria, e no periculum in mora (mencionado periculum libertatis) que se justifica nos motivos pelos quais o acusado não deve ser posto em liberdade por comprometer a garantia da ordem pública ou econômica (verdadeira ideia de ordem e paz social); a ordem econômica (que se liga ao planejamento e execução econômica do Estado; a conveniência da instrução criminal (traduzindo o pensamento de regular desenvolvimento do processo na busca da verdade); e, também, para assegurar a aplicação da lei penal (fundada nas evidências de o réu não cumprir a sanção penal), (GOMES, 2011).

Nesse sentido, extrai-se do Pacto Internacional de Direitos Civis e Políticos, (ONU, 1996) artigo 9º número três:

[...] Qualquer pessoa presa ou encarcerada em virtude de infração penal deverá ser conduzida, sem demora, à presença do juiz ou de outra autoridade habilitada por lei a exercer funções judiciais e terá o direito de ser julgada em prazo razoável ou de ser posta em liberdade. A prisão preventiva de pessoas que aguardam julgamento não deverá constituir a regra geral, mas a soltura poderá estar condicionada a garantias que assegurem o comparecimento da pessoa em questão à audiência e a todos os atos do processo, se necessário for, para a execução da sentença.

Desse pensamento, destaca-se a nova a Lei 12.403/11, a qual pregou a segregação cautelar como medida de extrema ratio da ultima ratio. Dessa máxima desenvolve que, juridicamente, analisando o fato, o magistrado deverá condicionar a prisão do acusado no centro da necessidade de tal medida, com um decreto devidamente fundamentado. 
Isso consta da CRFB/88, em seu artigo 93, inciso IX, que dispõe: "todos os julgamentos dos órgãos do Poder Judiciário serão públicos, e fundamentadas todas as decisões, sob pena de nulidade [...]”.

Consolidou-se, portanto, a necessidade das decisões emanadas dos órgãos judiciais estarem arrazoadas, concretizadas em elementos que motivaram respectiva decisão, em consonância com a Constituição. Diante disso, tem-se consignado o princípio da motivação nas decisões judiciais, o qual, consoante Nery Jr., é manifestação do princípio do devido processo legal (NERY JR e NERY, 2009, p. 455/456).

No mesmo sentido, Antônio Magalhães Gomes Filho, faz uma análise do art. 93, IX, da CRFB/1988, dizendo:

[...] $\mathrm{Na}$ redação adotada, dois pontos fundamentais merecem ser desde logo ressaltados, [...]. O primeiro diz respeito à extensão do dever judicial de motivar: ao referir-se a todas as decisões, o constituinte evidentemente pretendeu incluir nessa exigência todo e qualquer pronunciamento jurisdicional que contenha uma carga decisória, mínima que seja, só estando excluídos, portanto, os denominados despachos de expediente. O segundo está relacionado à previsão da sanção de nulidade no próprio texto constitucional: além de constituir uma novidade, tanto no nosso ordenamento como em relação ao direito constitucional comparado, isso revela a gravidade dos vícios de motivação, pois a falta de motivos ou a fundamentação deficiente ou contraditória mutilam a própria integridade do ato judicial (A motivação das decisões penais. São Paulo: RT, 2001. p. 71-72).

Quanto aos dispositivos concernentes ao tema, destaca-se o artigo 315 do Código de Processo Penal, o qual dispõe que "A decisão que decretar, substituir ou denegar a prisão preventiva será sempre motivada".

Desse modo, acerca da fundamentação no campo da prisão preventiva, é reiterado na jurisprudência, bem como amplamente majoritário na doutrina, que não são suficientes apenas motivos fundados nas questões e circunstâncias abstratas do delito, mas sim seja o decreto fundamentado no caso concreto.

Nesse raciocínio, ensina Ada Pelegrini Grinover:

[...] em face das garantias asseguradas ao cidadão pela Constituição - diante do texto expresso do art. 387, parágrafo único, sua decretação não pode ser automática, diante do reconhecimento da existência do crime e de sua autoria, mas deve resultar da apreciação sobre a presença do periculum libertatis, levando em conta os fatos e as exigências cautelares que se apresentam no momento da decisão que reconhece a procedência da acusação. Por isso, a falta de efetiva apreciação da necessidade da cautela importará [...] vício de fundamentação capaz de fazer incidir a sanção de nulidade por desatendimento aos preceitos constitucionais e legais indicados. (GRINOVER, 277, grifo não original). 
Urge destacar a súmula criminal número 32 do Egrégio Tribunal de Justiça de Minas Gerais, a qual dispõe que "A prisão preventiva deve ser, sempre, fundamentada com dados objetivos do processo".

Segundo Renato Brasileiro de Lima, "o juiz deve apontar, de maneira concreta, as circunstâncias fáticas que apontam no sentido da adoção da medida cautelar, sob pena de manifesta ilegalidade do decreto prisional" (LIMA, p. 286).

Diante dessa necessidade, "caso a decisão preferida pela autoridade judiciária competente não esteja devidamente fundamentada, haverá constrangimento ilegal ensejador de pedido de habeas corpus, pleiteando a cassação da prisão preventiva". (LIMA, p. 286).

Insta ressaltar que cabe ao órgão ministerial, também, fundamentar seus pareceres, consoante dispõe o artigo 43, inciso III, da Lei nº 8.625 de 1993 (Lei Orgânica do Ministério Público).

No tocante ao princípio da presunção de inocência, bem como sua análise no campo dos antecedentes criminais, necessário que se percorra com mais detalhe acerca desse princípio.

A CRFB/1988 trouxe duas consequências imediatas sentidas no âmbito processual penal, quais sejam, a instituição de um princípio afirmativo da situação de inocência de todo aquele que estiver submetido à persecução penal e a garantia de que toda prisão seja efetivamente fundamentada e por ordem escrita de autoridade judiciária competente.

Dessa máxima, o reconhecimento da condição de inocente (art. $5^{\circ}$, LVII) faz que seja imperativa necessidade de fundamentação judicial para toda e qualquer privação da liberdade, vez que somente o judiciário poderá determinar a prisão de um suposto criminoso. Ademais, tal embasamento deve estar pautado na indispensabilidade, na proporcionalidade e na necessidade da medida.

\section{Ensina Weber Martins Batista:}

[...] A presunção de inocência vale como uma ideia-força, no sentido de impedir que o réu seja tratado como seja estivesse condenado, que sofre restrições de direito que não sejam necessárias à apuração dos fatos e ao cumprimento da lei penal, em suma, que não seja tratado como mero objeto de investigações, mas como sujeito de direitos, gozando de todas as garantias comuns ao devido processo legal, sobretudo às garantias da plena defesa. (BATISTA, p. 1981).

Diante disso, o princípio da presunção de inocência se caracteriza na ideia de que até o trânsito em julgado da sentença penal condenatória o réu merece ser tratado como se inocente.

Nesse raciocínio, é de se destacar posições da Suprema Corte: 
[...] Ementa: HABEAS CORPUS. PROCESSUAL PENAL. PACIENTE DENUNCIADO PELA SUPOSTA PRÁTICA DOS CRIMES DE QUADRILHA E ESTELIONATO. PRISÃO PREVENTIVA. AUSÊNCIA DE FUNDAMENTAÇÃO IDÔNEA. MEDIDA LIMINAR INDEFERIDA NO SUPERIOR TRIBUNAL DE JUSTIÇA. SÚMULA 691. SUPERAÇÃO. ORDEM CONCEDIDA. I - A superação da Súmula 691 do STF constitui medida excepcional, que somente se legitima quando a decisão atacada se mostra teratológica, flagrantemente ilegal ou abusiva. A situação, no caso concreto, é excepcional, apta a superar o entendimento sumular, diante do evidente constrangimento ilegal ao qual está submetido o paciente. II - A prisão, antes da condenação definitiva, pode ser decretada segundo o prudente arbítrio do magistrado, quando evidenciada a materialidade delitiva e desde que presentes indícios suficientes de autoria. Mas ela deve guardar relação direta com fatos concretos que a justifiquem, sob pena de se mostrar ilegal. III No caso sob exame, o decreto de prisão preventiva baseou-se, especialmente, na gravidade abstrata dos delitos supostamente praticados e na comoção social por eles provocada, fundamentos insuficientes para se manter o paciente na prisão. IV Segundo remansosa jurisprudência desta Suprema Corte, não basta a gravidade do crime e a afirmação abstrata de que os réus oferecem perigo à sociedade para justificar a imposição da prisão cautelar. Assim, o STF vem repelindo a prisão preventiva baseada apenas na gravidade do delito, na comoção social ou em eventual indignação popular dele decorrente, a exemplo do que se decidiu no HC 80.719/SP, relatado pelo Ministro Celso de Mello. V Este Tribunal, ao julgar o HC 84.078/MG, Rel. Min. Eros Grau, firmou orientação no sentido de que ofende o princípio da não culpabilidade a execução da pena privativa de liberdade antes do trânsito em julgado da sentença condenatória, ressalvada a hipótese de prisão cautelar, desde que presentes os requisitos autorizadores previstos no art. 312 do Código de Processo Penal. VI - Ordem concedida para assegurar ao paciente o direito de aguardar em liberdade o trânsito em julgado de eventual sentença condenatória, sem prejuízo da aplicação de uma ou mais de uma das medidas acautelatórias previstas no art. 319 do Código de Processo Penal, estendendo-se a ordem aos corréus nominados no acórdão.( HC 118684 / ES, Rel. Min. RICARDO LEWANDOWSKI, Segunda Turma, julgado em 03/12/2013 , DJe 13/12/2013, grifo não original).

Quanto ao princípio da presunção de inocência, emergido pela doutrina, destaca-

se:

[...] se a jurisdição é atividade necessária para obter a prova de que um sujeito cometeu um crime, desde que tal prova não tenha sido encontrada mediante um juízo regular, nenhum delito pode ser considerado cometido e nenhum sujeito pode ser reputado culpado nem submetido a pena. Sendo assim, o princípio da submissão à jurisdição - exigindo, em sentido lato, que não haja culpa sem juízo, e, em sentido estrito, que não haja juízo sem que a acusação se sujeite à prova e à refutação postula a presunção de inocência do imputado até prova contrária decretada pela sentença definitiva de condenação. Trata-se, como afirmou Luigi Lucchini, de um "corolário lógico do fim racional consignado ao processo" e também a "primeira e fundamental garantia que o procedimento assegura ao cidadão: presunção juris, como sói dizer-se, isto é, até prova contrária". A culpa, e não a inocência, deve ser demonstrada, e é a prova da culpa - ao invés da de inocência, deve ser demonstrada, e é a prova da culpa - ao invés da de inocência, presumida desde o início - que forma objeto do juízo. (FERRAJOLI, 2010, p. 505-506).

Consoante ensina Gomes Filho, no sistema inquisitório medieval, a pessoa que era acusada deveria provar a sua inocência, haja vista o peso da visão a sociedade sobre a conduta praticada pelo agente (GOMES FILHO, 1991, p. 10). 
Com a revolução liberal do século XVIII, o princípio da presunção de inocência emergiu ao passo que também emergia a liberdade individual face às arbitrariedades do Estado (ANDRADE, 2003, p. 47).

Nessa oportunidade, destaca-se o pensamento de Cesare Beccaria, o qual afirmou que:

[...] um homem não pode ser considerado culpado antes da sentença do juiz; e a sociedade só lhe pode retirar a proteção pública depois que ele se convenceu de ter violado as condições com as quais estivera de acordo. O direito da força só pode, pois, autorizar um juiz a infligir uma pena a um cidadão quando ainda se duvida se ele é inocente ou culpado. (BECCARIA, p.22, 2006).

Segundo narra Ferrajoli, a prisão preventiva e o princípio da presunção de inocência estão estritamente ligados, haja vista que, com o desenvolver da cautelar, fez-se necessário o desenvolvimento aprimorado do princípio sobredito (FERRAJOLI, p. 508).

Sob a ótica do princípio da presunção de inocência, não se admitem as prisões automáticas, ou seja, apenas analisadas na lei, bem como o reconhecimento de maus antecedentes criminais somente pela constatação de inquérito policial ou de processo em andamento.

É pacificado na Suprema Corte que a prisão preventiva só é considerada legítima quando embasada em elementos concretos, sendo afastadas as prisões decretadas com fulcro em termos abstratos e genéricos.

Diante do exposto, não há que se retirar a razão da Suprema Corte, haja vista a necessidade da fundamentação do decreto preventivo se encontrar embasado nas circunstâncias concretas do delito.

A preocupação com as decisões motivadamente fundamentadas se dá em virtude de eliminar do ordenamento jurídico decisões arbitrárias e abusivas e, consoante Beck, evitar que decisões genéricas se tornem reiteradas. (BECK, 2001, p.79).

Nesse sentido, Rogerio Machado Cruz Schiett acrescenta que:

[...] ao analisar pedido de prisão preventiva, ou mesmo se já preso o acusado, para manter a custódia de forma legítima, deverá avaliar, diante das circunstâncias concretas deduzidas na acusação e já acolhidas na instrução criminal, se a pena que resultará de eventual sentença condenatória justifica o encarceramento preventivo, porquanto é bem possível que a sanção criminal que se antevê aplicável ao caso concreto seja bem inferior ao máximo cominado em abstrato para o ilícito em apuração. Com efeito, aparenta-se irrazoável suprimir a liberdade de alguém a título de prisão cautela, se essa pessoa, ao cabo do processo, não será efetivamente encarcerada a título de prisão pena. (SCHIETT, 2006). 
Diante de tais considerações, deve-se registrar que o decreto de prisão preventiva, por ser um ato que restringe, antecipadamente, a liberdade do indivíduo, possui caráter de medida gravosa, necessitando estar vinculado às circunstâncias concretas do delito.

Acrescenta-se, assim, que um decreto preventivo, pautado apenas nos antecedentes criminais do agente, coloca em risco a credibilidade do poder judiciário no que concerne à segurança jurídica e social, devendo, portanto, ter-se como referência a liberdade individual do agente, além dos princípios constitucionais.

Atentando-se aos princípios constitucionais da presunção de inocência, art. $5^{\circ}$, inciso LVII, faz-se necessário que a preponderância dos antecedentes criminais nas decisões que decretam a prisão preventiva não seja pautada apenas no estigma dos maus antecedentes, mas sim na cumulação dos requisitos legais com a análise do caso concreto, sem acrescentar aos antecedentes criminais dosagem subjetiva, ampla, negativa ou perpétua.

Desse modo, observando o fim especial da prisão, bem como os ditames dos princípios constitucionais, o direito penal, tratando-se de uma ciência dinâmica, precisa suavizar os protocolos jurídicos e as normas estáticas, correndo o risco de ficar obsoleto e de se distanciar do seu objetivo primordial, que é a ressocialização do sujeito criminalizado.

\subsection{Direito ao esquecimento}

Em consonância com o direito comparado, é relevante, diante do tema em estudo, que se percorra, brevemente, sobre o direito ao esquecimento. Foi no caso Lebach, analisado no Tribunal Constitucional Alemão, que surgiram as primeiras linhas sobre a tutela do direito ao esquecimento. O referido caso trata da chacina de quatro soldados alemães, em que dos suspeitos, dois foram condenados à prisão perpétua. Um terceiro autor fora condenado a seis anos de reclusão. Próximo a exaurir sua pena e voltar à sociedade, uma emissora televisiva editou uma reportagem trazendo à tona, por meio de simulação, todo o caso, bem como a identificação dos acusados. Diante do fato, o acusado pugnou, em sede liminar, que a reportagem não fosse transmitida.

Em análise do caso, o Tribunal Constitucional Alemão entendeu pela proteção constitucional do direito da personalidade do condenado face à sua dificuldade de ressocialização, haja vista a exploração ilimitada da vida pregressa do condenado pela sociedade. 
Feito esse breve resumo, verifica-se presente no direito penal e no processual penal pátrio a tutela pelo direito ao esquecimento, apesar de seu reconhecimento está expresso no âmbito do direito civil, no enunciado 531 da VI Jornada de Direito Civil do CJF, o qual dispõe que "a tutela da dignidade da pessoa humana na sociedade da informação inclui o direito ao esquecimento", in verbis:

ENUNCIADO 531 - A tutela da dignidade da pessoa humana na sociedade da informação inclui o direito ao esquecimento. Artigo: 11 do Código Civil. Justificativa: Os danos provocados pelas novas tecnologias de informação vêm-se acumulando nos dias atuais. $\mathrm{O}$ direito ao esquecimento tem sua origem histórica no campo das condenações criminais. Surge como parcela importante do direito do exdetento à ressocialização. Não atribui a ninguém o direito de apagar fatos ou reescrever a própria história, mas apenas assegura a possibilidade de discutir o uso que é dado aos fatos pretéritos, mais especificamente o modo e a finalidade com que são lembrados.

No Brasil, no âmbito das relações privadas, a questão foi analisada em duas decisões proferidas pelo STJ, ressaltando a necessidade da vida passada das pessoas ser esquecida, devendo, portanto, evitar a divulgação dos delitos praticados no passado.

Segundo o Ministro Luís Felipe Salomão, há diversos dispositivos no sistema jurídico pátrio ensejadores do reconhecimento ao direito ao esquecimento, como por exemplo, o artigo 93 do CP, o artigo 748 do CPP, bem com o artigo 202 da Lei de Execuções Penais, no qual este dispõe:

Art. 202. Cumprida ou extinta a pena, não constarão da folha corrida, atestados ou certidões fornecidas por autoridade policial ou por auxiliares da justiça, qualquer notícia ou referência à condenação, salvo para instruir processo pela prática de nova infração penal ou outros casos expressos em lei.

Nessa esteira, veja-se:

[...] os condenados que já cumpriram a pena tem direito ao sigilo da folha de antecedentes, assim também a exclusão dos registros da condenação no Instituto de Identificação, por maiores e melhores razões aqueles que foram absolvidos não podem permanecer com esse estigma, conferindo-lhes a lei o mesmo direito de serem esquecidos. (Ministro Luís Felipe Salomão, Resp.1.334.097- RJ, 2012/0144910-7 de 10/09/2013).

RECURSO ESPECIAL. PENAL. INQUÉRITO POLICIAL. ARQUIVAMENTO. INCLUSÃO DO NOME NOS TERMINAIS DO INSTITUTO DE IDENTIFICAÇÃO. SIGILO DAS INFORMAÇÕES. "Se o Código de Processo 
Penal, em seu art. 748, assegura ao reabilitado o sigilo de registro das condenações criminais anteriores, é de rigor a exclusão dos dados relativos a sentenças penais absolutórias e inquéritos arquivados dos terminais de Instituto de Identificação, de modo a preservar as franquias democráticas consagradas em nosso ordenamento jurídico.” Recurso provido. (REsp 443.927/SP, Rel. Ministro JOSÉ ARNALDO DA FONSECA, QUINTA TURMA, julgado em 10/06/2003, DJ 04/08/2003, p. 366)

Ante o exposto, embora o pouco debate no direito brasileiro, percebe-se que, com a tutela do direito ao esquecimento, a personalidade do agente, muito embora este tenha cometido algum delito no passado, deve ser respeitada e, quando analisada para fins judiciais, desvincular-se do caráter negativo do seu passado.

Objetivando-se eliminar excessos e arbitrariedades nas decisões judiciais que decretam a prisão preventiva, vislumbra-se a necessidade de uma análise dinâmica e restrita às circunstâncias concretas do delito por parte dos julgadores.

Com efeito, para que o órgão julgador não se fundamente apenas pelas primeiras impressões que uma certidão de antecedentes criminais reflete, é mais que aconselhável que se faça uma análise das informações que constam dos autos, levantando-se todos os dados possíveis da vida do agente, como sua vida profissional, social e familiar, para que não se fique limitado apenas nas no caráter negativo do seu passado.

Ante toda exposição, caso o magistrado atribua relevante valoração aos antecedentes criminais, mesmo quando não presentes os requisitos da prisão preventiva, estarse-ia, assim, violando o princípio constitucional da presunção de inocência.

A utilização dos antecedentes criminais como modo de aferir a necessidade da prisão cautelar, fazendo-se uma análise da futura possibilidade de o agente delinquir, face à sua certidão negativa, é medida que não merece acolhida quando ausentes os requisitos autorizadores da prisão preventiva.

Nesse diapasão, é o voto do relator Amilton Bueno de Carvalho:

[...] A prisão preventiva - extemporânea e temerária - só é admissível nos casos extremos: preponderância do princípio da presunção de inocência. E neles, os casos limítrofes, a decisão segregativa exige esteio em sérios, claros e fortes fundamentos - tal exigência nada mais é do que a aplicação da regra do art. 93, IX da CF/88: necessidade. (HC 70006140693, QUINTA CẨMARA CRIMINAL, TJRS).

Portanto, vislumbra-se que o decreto de prisão preventiva, valorado exclusivamente na vida pregressa do agente, pode resultar em aplicação de uma sanção antecipada, bem como é caracterizada por violar o princípio constitucional da presunção de inocência; sobretudo 
quando o julgador não possui motivos ensejadores da medida cautelar, o que gera a sensação de se estar diante de uma nítida insegurança jurídica.

\section{CONSIDERAÇÕES FINAIS}

Evidenciou-se, ao longo da história jurídica, que a influência dos antecedentes criminais nas decisões judiciais é perceptível. Tal relevância pode ser observada nos decretos de prisões preventivas, os quais, muitas vezes, fogem da valoração concreta do caso e se baseiam apenas na periculosidade do agente em face de seus antecedentes criminais.

Contudo, à luz da atual interpretação constitucional da ciência criminal e do modelo garantista, viu-se que se deve observar o caráter excepcional da medida cautelar, para não se ter uma decisão arbitrária e baseada no estigma que os antecedentes criminais carregam.

Constatou-se que, conforme o artigo 93, inciso IX, da CRFB/1988, todos os julgamentos dos órgãos do poder judiciário serão públicos e fundamentadas todas as decisões, sob pena de nulidade. Desse mandamento, é forçosa a necessidade de se trazer à baila os motivos e requisitos autorizadores da medida cautelar, evitando-se proferir uma decisão calcada apenas no estigma dos antecedentes criminais, aos quais possuem um caráter punitivo-perpétuo.

Nesse diapasão, vislumbra-se que a segregação do agente nas decisões que decretam a prisão preventiva não pode ser pautada apenas no estigma dos maus antecedentes, mas sim na cumulação dos requisitos legais com a análise do caso concreto, sem acrescentar aos antecedentes criminais dosagem subjetiva, ampla, negativa e perpétua.

Desse modo, é importante que se analise concreta e conjuntamente todos os fatores que circundam o caso, evitando-se a insegurança jurídica e social, já que a regra é a liberdade do indivíduo e o seu encarceramento é medida de extrema exceção.

\section{REFERÊNCIAS}

ANGHER, Anne Joyce. Vade Mecum Acadêmico de Direito. 14. ed. São Paulo Rideel, 2012. 
BARRAL, Welber. Metodologia da pesquisa jurídica. 3. ed. Florianópolis: Fundação Boiteux, 2010.

BARROS, Flávio Augusto Monteiro de, Direito Penal - Parte Geral, v. 1, São Paulo, Saraiva, 1999.

BECCARIA, Cesare, Dos Delitos e Das Penas. São Paulo: Matin Claret, 2006.

BECK, R. F. Apontamentos críticos sobre a prisão provisória no direito processual penal brasileiro. Revista de Estudos Criminais, Porto Alegre,1, n. 4, dez. 2001.

BRASIL. Constituição da República Federativa do Brasil, de 05 de outubro de 1988. São Paulo: Saraiva, 2011.

Decreto-Lei n . 2.848, de 07.12.1940. Código Penal. São Paulo: Saraiva, 2012.

BATISTA, Weber Martins. Liberdade provisória. Rio de Janeiro: Forense, 1981.

BISSOLI FILHO, Francisco. Estigmas da criminalização: dos antecedentes à reincidência criminal. Florianópolis: Obra Jurídica, 1998.

BONFIM, Edilson Mougenot. Curso de Processo Penal. 4. ed. São Paulo: Saraiva, 2009.

CARVALHO, Kildare Gonçalves. Direito Constitucional. ed. 10. Belo Horizonte: DelRey, 2004.

CARVALHO, Salo de. Reincidência e antecedentes criminais: abordagem crítica desde o marco garantista. Revista de estudos criminais, Porto Alegre, 2001.

CAPEZ, Fernando. Curso de processo penal. 19. ed. São Paulo: Saraiva, 2012.

CINTRA, Antonio Carlos de Araújo; GRINOVER, Ada Pellegrini; DINAMARCO, Cândido Rangel. Teoria geral do processo. 13. ed. São Paulo: Malheiros, 1997.

COSTA, António Manuel de Almeida. O registro criminal. Coimbra: Gráfica de Coimbra, 1985.

FERRAJOLI, Luigi. Direito e Razão. Teoria do Garantismo Penal. Tradução Coletiva.

São Paulo: RT, 2010.

, Luigi. Direito e razão: teoria do garantismo penal. 2. ed. rev. e ampl. São Paulo: Revista dos Tribunais, 2006.

GOMES, Luiz Flavio; SILVA, Ivan Luís Marques da. Prisão e medidas cautelares: comentários à Lei 12.403/2011. 2. ed. São Paulo: RT, 2011.

GRINOVER, Ada Pelegrini et al. Juizados especiais criminais: comentários à Lei 9.099, de 26.09.1995. 4. ed. rev. ampl. e atual. São Paulo: Revista dos Tribunais, 2002.

Ada Pelegrini. Liberdades públicas e processo penal. 2. ed. São Paulo: RT, 1982. 
LEITE FILHO, Nelson. Antecedentes criminais. Revista dos Tribunais, São Paulo, v. 778, ago. 2000.

LIMA, Renato Brasileiro de. Nova prisão cautelar: de acordo com a Lei n. 12.403/11, doutrina, jurisprudência e prática. Niterói: Impetus, 2011.

MASSON, Cleber. Direito penal esquematizado: parte especial - vol. 2. $6^{\mathrm{a}}$ ed. Ver. E atual - Rio de Janeiro: Forense; São Paulo: Método, 2014.

MOYANO, Hélio A. Nogues. Um critério Objetivo de antecedentes criminais. Boletim IBCrim, São Paulo, n.8, set. 1993.

NERY JR. Nelson. NERY, Rosa Maria de Andrade. Constituição Federal Comentada. 2. ed. São Paulo: RT, 2009.

NOGUEIRA, Carlos Frederico Coelho. Comentários ao Código de Processo Penal. v. 1. ed. São Paulo: Edipro, 2002.

NUCCI, Guilherme de Souza. Individualização da Pena. 3. ed. São Paulo: RT. 2009.

Princípios Constitucionais Penais e Processuais Penais. São Paulo: RT. 2010.

. Prisão e Liberdade. As reformas processuais penais introduzidas pela lei $12.403 \mathrm{de}$ 4 de maio de 2011. São Paulo: RT. 2011.

ONU. Pacto Internacional dos Direitos Civis e Políticos.

PEDROSO, Fernando de Almeida. Processo penal; o direito de defesa: repercussão, amplitude e limites. Rio de Janeiro: Forense, 1986.

PIERANGELI, José Henrique. Códigos Penais do Brasil: evolução histórica. 2. ed. São Paulo: Revista dos Tribunais, 2001.

SCHIETTI, Rogerio Machado Cruz. Prisão Cautelar: Dramas, Princípios e Alternativas. Rio de Janeiro: Lumen Juris, 2006.

TÁVORA, Nestor; ALENCAR, Rosmar Rodrigues. Curso de direito processual penal. Bahia: JusPodivm, $9^{\mathrm{a}}$ ed, 2014.

TEDESCO WENDY, Miguel. Teoria Geral da Prisão Cautelar e Estigmatização. Rio de Janeiro: Lúmen Juris, 2006.

TORNAGHI, Hélio. Manual de processo penal: prisão e liberdade. Rio de Janeiro: Freitas Bastos, 1963. v.1.

TORON, Alberto Zacharias. A Constituição de 1988 e o conceito de bons antecedentes para apelar em liberdade. Revista Brasileira de Ciências Criminais, São Paulo, v. 4, out. 1993.

TOURINHO FILHO, Fernando da Costa. Código de Processo Penal Comentado. 3. ed. São Paulo: Saraiva,1998. 
ZAFFARONI, Eugenio Raúl. Reincidência: um conceito do direito penal autoritário. Rio de Janeiro: Instituto de Estudos Jurídicos, 1993.

STF, Supremo Tribunal de Justiça.

STJ, Superior Tribunal de Justiça. Disponível em:

$<$ http://www.stj.jus.br/SCON/jurisprudencia/doc.jsp?livre=INQU\%C9RITOS+POLICIAIS+ MAUS+ANTECEDENTES\&\&b=ACOR\&p=true \&t=JURIDICO\&l=10\&i=11 > Acesso em: 22 de julho de 2014.

STJ, Superior Tribunal de Justiça. Disponível em:

$<$ https://ww2.stj.jus.br/revistaeletronica/Abre_Documento.asp?sLink=ATC\&sSeq=4183606\& sReg=200702745937\&sData=20081117\&sTipo=91\&formato=PDF $>$ Acesso em: 06 janeiro. 2013.

STJ, Superior Tribunal de Justiça. Disponível em: < https://ww2.stj.jus.br/revistaeletronica/Abre_Documento.asp?sLink=ATC\&sSeq=2424862\&s Reg=200501790702\&sData=20060801\&sTipo=91\&formato=PDF $>$ Acesso em: 20 de maio 2013.

STJ, Superior Tribunal de Justiça. Disponível em:

$<$ https://ww2.stj.jus.br/revistaeletronica/Abre_Documento.asp?sLink=ATC\&sSeq=2477164\& sReg=200601036390\&sData=20060801\&sTipo=51\&formato=PDF $>$ Acesso em: 20 de maio. 2013.

STJ, Superior Tribunal de Justiça. Disponível em:

https://ww2.stj.jus.br/revistaeletronica/Abre_Documento.asp?sLink=ATC\&sSeq=18729968\& sReg $=201102158502 \&$ sData=20111128\&sTipo=51\&formato=PDF. Acesso em 04 de agosto. 2013.

Disponível em: http://s.conjur.com.br/dl/direito-esquecimento-acordao-stj.pdf. Acesso em: 05 de julho. 2013.

TJMG, Tribunal de Justiça do Estado de Minas Gerais. Disponível em:

<http://www5.tjmg.jus.br/jurisprudencia/pesquisaPalavrasEspelhoAcordao.do?\&numeroRegis tro $=1 \&$ totalLinhas $=1 \&$ paginaNumero $=1 \&$ linhasPorPagina $=1 \&$ palavras $=1.0000 .13 .051780$ 8/000\&pesquisarPor=acordao\&pesquisaTesauro=true\&orderByData=1\&referenciaLegislativa $=$ Clique $\% 20$ na $\% 201$ upa $\% 20$ para $\% 20$ pesquisar $\% 20$ as $\% 20$ refer $\%$ EAncias $\% 20$ cadastradas...\& pesquisaPalavras=Pesquisar\& $>$ Acesso em: 23 junho. 2013. 